\title{
Purification, Characterization and Thermodynamic Assessment of an Alkaline Protease by Geotrichum Candidum of Dairy Origin
}

\author{
Abubakar Muhammad ${ }^{1}$, Syed Ali Imran Bokhari ${ }^{2}$, Jean-Paul Vernoux ${ }^{3}$, Muhammad Ishtiaq Ali ${ }^{1}$, Rani \\ Faryal $^{1}$, Nathalie Desmasures ${ }^{3}$, Muhammad Imran ${ }^{1, *}$ \\ ${ }^{1}$ Department of Microbiology, Faculty of Biological Sciences, Quaid-i-Azam University, Islamabad, Pakistan \\ ${ }^{2}$ Department of Bioinformatics and Biotechnology, International Islamic University, Islamabad, Pakistan \\ ${ }^{3}$ Aliments Bioprocédés Toxicologie Environnement (ABTE), E.A. 4651, Université de Caen Basse-Normandie, Esplanade \\ de la Paix, CAEN Cedex, France
}

\footnotetext{
* Corresponding author: Muhammad Imran, Department of Microbiology, Faculty of Biological Sciences, Quaid-i-Azam University, Islamabad, Pakistan; Tel: +923190643183; E-mail: mmimran@qau.edu.pk
}

\begin{abstract}
Background: Alkaline proteases is the important group of enzymes having numerous industrial applications including dairy food formulations.

Objectives: The current study deals with the purification and characterization of an alkaline serine protease produced by Geotrichum candidum QAUGC01, isolated from indigenous fermented milk product, Dahi.

Material and Methods: In total twelve G. candidum strains were screened for their proteolytic activity by using standard protease assay. The protease production from G. candidum QAUGC01 was optimized by varying physiochemical conditions. The protease was purified by using two-step method: ammonium sulfate precipitation and gel filtration chromatography. Protease was further characterized by studying various parameter like temperature, $\mathrm{pH}$, modulators, metal ions and organic solvent. A thermodynamic study was also carried out to explore the half-life of protease.

Results: The G. candidum grew profusely at $25^{\circ} \mathrm{C}$ and at an initial $\mathrm{pH}$ of 4.0 for $72 \mathrm{~h}$ of incubation producing 26.21 $\mathrm{U} / \mathrm{ml}$ maximum extracellular protease. Protease revealed that $V_{\max }$ and $K_{m}$ was $26.25 \mathrm{U} \cdot \mathrm{ml}^{-1} \cdot \mathrm{min}^{-1}$ and $0.05 \mathrm{mg} \cdot \mathrm{mL}^{-1}$, respectively using casein as substrate. The enzyme was stable at a temperature range $\left(25-45^{\circ} \mathrm{C}\right)$ and $\mathrm{pH}(8-9)$. Residual enzyme activity was strongly inhibited in the presence of PMSF (7.5\%). The protease could hydrolyze proteinaceous substrates, casein (98\%) and BSA (95\%). The thermodynamic studies explored that the half-life of the enzyme that was $106.62 \mathrm{~min}, 38.72 \mathrm{~min}$ and $15.71 \mathrm{~min}$ at 50,60 and $70{ }^{\circ} \mathrm{C}$, respectively.

Conclusions: Purified protease from G. candidum GCQAU01 is an ideal candidate for industrial application.
\end{abstract}

Keywords: Geotrichum candidum; Alkaline Serine Protease, Kinetics; Thermodynamics

\section{Background}

Nearly two-third of commercial proteases are produced by fungal species, yeasts and bacteria (1). Proteases (EC 3.4.21) are the significant class of industrially produced enzymes, which constitute around $60 \%$ of the total world enzyme production (2). Proteases are exploited in the food, dairy, leather, detergents and brewing industries (3). Proteases also have health and medical applications for instance: tissue inflammation reduction and burns treatment (4).

Thousands of proteases have been isolated from plants, animal tissues and microorganisms. Among these sources, microorganisms especially, bacteria and fungi are preferred for their high enzyme production (5).
Alkaline proteases constitute $60-65 \%$ of the global industrial market. Alkaline serine proteases of microbial origin possess considerable industrial potential (6). Bacterial protease production requires cost intensive processes for the separation of enzymes from cells. To satisfy the escalating industrial need for potent enzymes, it is mandatory to search for novel enzymes with desired properties. This was the aim of the present work to use the well-known fungus Geotrichum Candidum, which is a dominant yeast in fermented dairy products to meet the industrial demands (7).

The G. candidum is widely distributed in dairy environment and naturally appears in raw milk, brines 
and equipment surface, and it was recently found in fermented milk product Dahi $(8,9)$. The G. candidum ranks high amongst the rapidly growing fungus and it is on the borderline between mold and yeasts. It has been classified as a filamentous yeast-like fungi. Microscopic examination of G. candidum showed arthroconidia formed by hyphal fragmentation and with creamcolored, yeast-like colonies. This uniqueness suggests that it belongs to imperfect fungi group (10). Safety assessment of G. candidum was reported (11) and technological beneficial used was recognized in "2002 IDF inventory" (12). Moreover, its genomic data was recently reported (13).

The industrial production of protease from G. candidum has not been exploited to a large extent (14). Presence of G. candidum extracellular proteases have been reported four decades ago (15) but no other study has followed since then.

\section{Objective}

The objective of the present study is the extracellular production of proteases by a proteolytic strain of $G$. candidum isolated from Dahi. Furthermore, characterization and assessment of thermodynamic properties of protease was also evaluated in laboratory conditions.

\section{Materials and Methods}

\subsection{Materials}

All the chemicals and reagents were commercial products of analytical or higher grade unless mentioned otherwise.

\subsection{Yeast strains and Culture Conditions}

G. candidum strains were isolated from indigenous fermented milk product (Dahi) by plating at $25^{\circ} \mathrm{C}$ on Oxytetracycline glucose agar (OGA) prepared by using $20 \mathrm{~g} / \mathrm{L}$ glucose and yeast extract 5 g. $\mathrm{L}^{-1}$, oxytetracycline 0.10 g. $\mathrm{L}^{-1}$ and $15 \mathrm{~g} . \mathrm{L}^{-1}$ agar $\mathrm{pH} 6.6 \pm 0.2$. The culture was stored in the form of slant at $4^{\circ} \mathrm{C}$. Pre-culturing of microbial isolates was done by transferring one colony from 5 days old OG agar slant of G. candidum having rich growth to $5 \mathrm{ml}$ of OG broth medium. After incubation at $25^{\circ} \mathrm{C}$ for $48 \mathrm{~h}$ under $200 \mathrm{rpm}$ shaking, culturing was done by transferring $1 \mathrm{ml}$ of pre-culture $\left(5 \pm 1 \times 10^{8}\right.$ cells per $\mathrm{mL}$ ) to $100 \mathrm{~mL}$ of the same broth

All isolated strains were selected for proteolytic activity based on appearance of clear hydrolysis zones on the casein agar plate (Nutrient agar with $1 \%$ casein) around the colonies. Microbial colonies that displayed the largest clearance zones, were purified and protease activity was assessed.

Three reference strains G. candidum UCMA 91 (ATCC 204307), G. candidum UCMA 103, G. candidum UCMA 322 were also used in the present study and which were obtained from Université de Caen, Normandy, France.

\subsection{Protease Assay}

The standard protease assay was used with casein as a substrate with minor modification to determine proteolytic activity (16). One International Unit (IU) of enzyme activity was expressed as the fraction of enzyme which produces one $\mu \mathrm{mol}$ of tyrosine $/ \mathrm{ml} / \mathrm{min}$. The protein concentration was measured by using BSA as a standard at $650 \mathrm{~nm}$.

\subsection{Media for Protease Production}

Effect of media composition on the production of protease was studied by cultivating the organism in five different growth broth media:

Maltose based medium (MPY; adapted from (17)) (g.L-

$\left.{ }^{1}\right)$ : Maltose 10.0; Peptone 2.5; yeast extract, 1.0, $\mathrm{Na}_{2} \mathrm{CO}_{3}$ 7.5, $\mathrm{K}_{2} \mathrm{HPO}_{4}$ 1.0.

Gelatin based medium (GCG; adapted from (18)) (g.L-

$\left.{ }^{1}\right)$ : gelatin $15 \mathrm{~g}$, casein hydrolysate 5.0 , and $3 \mathrm{ml}$ of glycerol (20\% in water);

Beef extract based medium (BPN; adapted from (19)) $\left(\mathrm{g} . \mathrm{L}^{-1}\right)$ : beef extract 1.0; peptone 5.0, Yeast Extract 2.0, $\mathrm{NaCl} 5.0$;

Peptone based medium (PYG; adapted from (20)) (g.L $\left.{ }^{1}\right)$ : peptone 10.0 , yeast extract 0.2 , glucose $1.0 ; \mathrm{K}_{2} \mathrm{HPO}_{4}$ 0.5 , calcium chloride 0.1 , and magnesium sulphate 0.1 ; Casein based medium (CGY; adapted from (21)) (g.L $\left.\mathrm{L}^{-1}\right)$ : glucose 10.0; casein 5.0, yeast extract 5.0; $\mathrm{K}_{2} \mathrm{HPO}_{4}$ 2.0, $\mathrm{KH}_{2} \mathrm{PO}_{4} 2.0, \mathrm{MgSO}_{4} 7 \mathrm{H}_{2} \mathrm{O} 0.1$.

The initial $\mathrm{pH}$ of these media was adjusted at 5.0 with $1 \mathrm{~N} \mathrm{HCL} / \mathrm{NaOH}$, since it has been reported to be in the range of optimal $\mathrm{pH}$ for $\mathrm{G}$. candidum growth and proteolysis (22). Each experiment was conducted at 25 ${ }^{\circ} \mathrm{C}$ in a one-liter conical flask, containing $250 \mathrm{~mL}$ of broth culture media inoculated with standardized inoculum, left under gentle agitation of $200 \mathrm{rpm}$ for $96 \mathrm{~h}$. The standard protease assay for the G. candidum QAUGC01 was performed while G. candidum growth was simultaneously assessed. The growth index of the microorganisms was determined by measuring absorbance of a diluted solution at $600 \mathrm{~nm}$.

\subsection{Purification of Protease}

All procedures were performed at $4{ }^{\circ} \mathrm{C}$. After $72 \mathrm{~h}$, the culture medium $(250 \mathrm{ml})$ was centrifuged at $4,000 \mathrm{rpm}$ for $30 \mathrm{~min}$ at $4^{\circ} \mathrm{C}$ (Kokusan Model H-251 centrifuge) and was filtered on filter paper (Whatman No. 1, Sigma Aldrich) to remove biomass. The filtrate was then precipitated with ammonium sulfate at $60 \%$ saturation. The precipitates was collected by centrifugation ( 8000 rpm for $10 \mathrm{~min}$ at $4{ }^{\circ} \mathrm{C}$ ), and mixed in $10 \mathrm{ml}$ Tris- $\mathrm{HCl}$ buffer ( $\mathrm{pH}$ 8.5). The crude protein was dialyzed and then subjected to Sephadex G-100 for gel filtration chromatography. In total five $\mathrm{mL}$ of protein precipitate suspension was carefully loaded and eluted by using 50 $\mathrm{mM}$ Tris-HCL buffer $\mathrm{pH} 8.5$ at a flow rate of 0.5 $\mathrm{mL} / \mathrm{min}$. Each $3 \mathrm{~mL}$ collected fractions were examined both for protease activity and total protein content estimation. The fractions with highest protease activity 
were pooled and then lyophilized. The molecular mass was estimated by SDS-PAGE.

\subsection{Characterization of Purified Protease}

\subsubsection{Effect of Substrate Concentration}

To assess the effect of different concentrations of substrate (casein) on enzyme activity, the purified enzyme was assayed by standard protein assay with varying substrate concentration from 0.3 to $0.025 \%$. $(\mathrm{w} / \mathrm{v})$. The Data obtained was plotted in the form of Lineweaver-Burk plot in order to calculate $K_{m}$ and $V_{\max }$ (23).

\subsubsection{Effect of Temperature, $p H$ and Inhibitors on Protease Activity}

To determine the effect of reaction temperature and $\mathrm{pH}$ on protease activity, the protease activity was assayed at temperature ranges from 5 to $65^{\circ} \mathrm{C}$ and $\mathrm{pH} 4$ to 13 . Stability of protease was determined by pre-incubation of the enzyme with a $\mathrm{pH}$ range of 4 to 13 . The effect of selected inhibitors; PMSF, EDTA, $\beta$-mercaptoethanol, ascorbic acid and cysteine, at $10 \mathrm{mM}$ concentration was examined by incubating purified enzyme solution and inhibitor for $1 \mathrm{~h}$ at $25^{\circ} \mathrm{C}$. The relative protease activities were determined under protease assay standard conditions.

\subsubsection{Effect of Metal Ions and Organic Solvents on} Protease Activity

The effect of various chloride salts of divalent ions $\left(\mathrm{Co}^{2+}\right.$, $\mathrm{Ca}^{2+}, \mathrm{Mn}^{2+}, \mathrm{Cu}^{2+}, \mathrm{Mg}^{2+}, \mathrm{Hg}^{2+}, \mathrm{Zn}^{2+}$ and $\mathrm{Cd}^{2+}$ ) of concentration $10 \mathrm{mM}$ were added separately in a reaction mixture for $1 \mathrm{~h}$ at $25^{\circ} \mathrm{C}$. The effect of different selected solvents was checked in separate conical flasks by adding each solvent at $10 \mathrm{mM}$ concentration for $1 \mathrm{~h}$ at $25^{\circ} \mathrm{C}$ and protease stability was determined by using the standard protease assay.

\subsubsection{Effect of Substrate Specificity}

The purified protease activity was examined at $1 \%$ $(\mathrm{w} / \mathrm{v})$ of varied proteinaceous substrates such as BSA, casein, skim milk, azo-casein and gelatin under the standard protease assay conditions.

\subsection{Thermodynamics of Enzyme}

Thermodynamic parameters related to irreversible denaturation of protease were calculated by incubating the protease in Tris-HCL buffer $(\mathrm{pH} 8.5)$ at four different temperatures i.e. $45,50,55$ and $60^{\circ} \mathrm{C}$. Aliquots were taken out and assayed at different times for enzyme activity. The data were plotted to the first order plots and analysed as described (23). The reaction rate constant for thermal inactivation $\left(k_{\mathrm{d}}\right)$ was determined from a logarithmic plot of percent of activity remaining versus time, according to the equation.

$\ln \%$ residual activity $=-k_{\mathrm{d}} \mathrm{t}(\mathrm{I})$

To determine the activation energy for thermal inactivation $\left(E_{\mathrm{a}}\right)$, an Arrhenius plot was obtained from a plot of $\ln \left(k_{\mathrm{d}}\right)$ versus $1 / T$ (temperature of incubation).
The line slope was calculated from the following equation:

$$
\operatorname{Ln}\left(k_{\mathrm{d}}\right)=-E_{\mathrm{a}} / R T(\mathrm{II})
$$

The half-life $\left(t_{1 / 2}\right)$ was calculated from the following equations:

$$
t_{1 / 2}=0.693 / k_{\mathrm{d}}(\mathrm{III})
$$

Thermodynamic parameters like enthalpy $(\Delta H)$ free energy $(\Delta G)$ and entropy $(\Delta S)$ were calculated as follows:

$$
\begin{gathered}
\Delta H=E_{\mathrm{a}}-R T(\mathrm{IV}) \\
\Delta G=-R T \ln \left(k_{\mathrm{cat}} h / k_{\mathrm{B}} T\right)(\mathrm{V}) \\
\Delta S=(\Delta H-\Delta G) / T(\mathrm{VI})
\end{gathered}
$$

\section{Results}

4.1. Screening and Characterization of Proteolytic Activity

Twelve strains of G. candidum were isolated from indigenously fermented milk product Dahi, were screened for protease activity along with three reference strains and results are given in (Fig. S1). All strains except QAUGC12 were identified as protease producers at different levels with an effective hydrolysis zone reaching 1 to $15 \mathrm{~mm}$ increasing of diameter around the microbial spot loaded.

\subsection{Effect of Fermentation Media}

Keeping in view the economic concerns involved in the fermentation process, the protease production was experimented with five different media. Beef extract based medium (BPN) gave the maximum yield with a specific activity of $26.21 \mathrm{Umg}^{-1}$ (Fig. S2A). Thus, medium BPN was used for further studies.

\subsection{Optimization of Various Cultural Conditions}

Four different incubation time periods 24, 48, 72 and 96 $\mathrm{h}$ were examined for the production of protease in BPN broth. Maximum protease production (26.21 $\mathrm{Umg}^{-1}$ ) was recorded after $72 \mathrm{~h}$ of incubation (Fig. S2B). A set of experiments were carried out at temperature range 15 ${ }^{\circ} \mathrm{C}-65^{\circ} \mathrm{C}$ to optimize the incubation temperature for protease production. A gradual increase in the incubation temperature the protease activity increased and reached to maximum at $25{ }^{\circ} \mathrm{C}\left(27.30 \mathrm{Umg}^{-1}\right)$. Finally, it reduced to minimum at $65{ }^{\circ} \mathrm{C}\left(10.0 \mathrm{Umg}^{-1}\right)$ (Fig. S2C). The effect of $\mathrm{pH}$ (3-11), on the production of protease was examined. Protease production was higher in the $\mathrm{pH}$ range 3 to 5 with a maximum at $\mathrm{pH} 4$ (that is also maximum growth $\mathrm{pH}$ ) with specific activity 28.9 $\mathrm{Umg}^{-1}$ but it was consistently decreased with an increase in $\mathrm{pH}$ which parallels growth behavior evaluated by growth index (Fig. S2D).

\subsection{Purification of Protease}

Summary of purification procedure of extracellular protease is summarized in Table 1. Protease was purified around 46 fold with specific activity of 34.60 IUmg $^{-1}$ (Table 1). The SDS-PAGE analysis revealed a single band with a molecular weight of $81 \mathrm{kDa}$ (Fig. 1). 


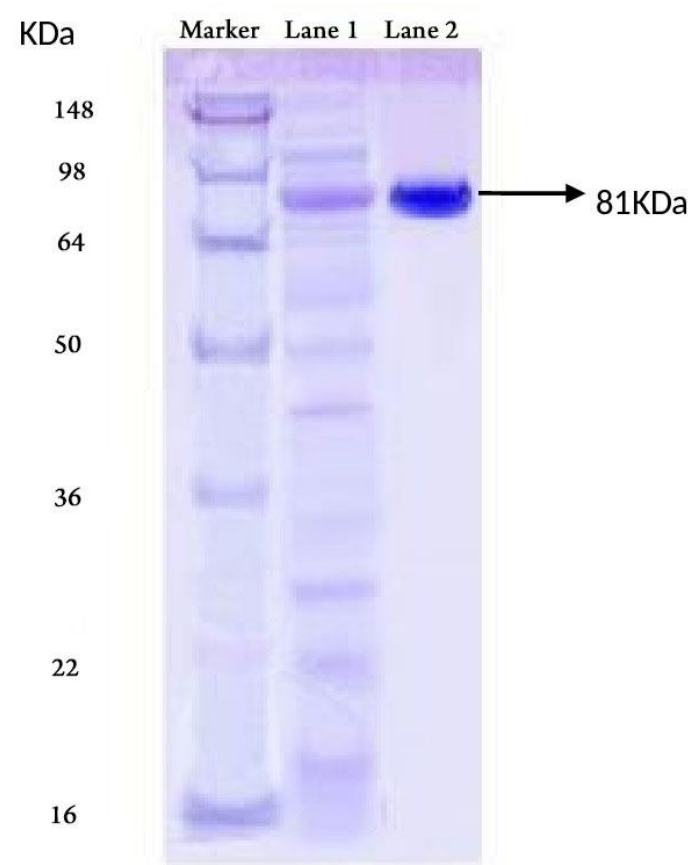

Figure 1. SDS-PAGE analysis of purified protease by G. candidum (QAUGC01) Lane 1, Crude enzyme, Lane 2 Purified Protease.

\subsection{Characterization of Purified Protease}

4.5.1. The effect of substrate concentration, temperature and $\mathrm{pH}$ on protease activity

The data on substrate effect on enzyme activity were plotted and kinetic constant were calculated. $V_{\max }$ was calculated as $26.25 \mathrm{U} / \mathrm{ml} / \mathrm{min}$ while $K_{m}$ was calculated $0.05 \mathrm{mg} / \mathrm{ml}$ (Fig. 2). Thermophilicity can accelerate the exploitation of enzyme in biotechnological processes to avoid contamination by common microorganism. Hence, the thermostability of purified enzyme was tested by imposing various temperature regimes (5-75 $\left.{ }^{\circ} \mathrm{C}\right)$. The relative activity of purified protease at $55^{\circ} \mathrm{C}$ was $141.54 \%$ (Fig. 3A). Purified protease showed maximum relative activity of $144.33 \%$ at $\mathrm{pH} 12$ (Fig. 3B).

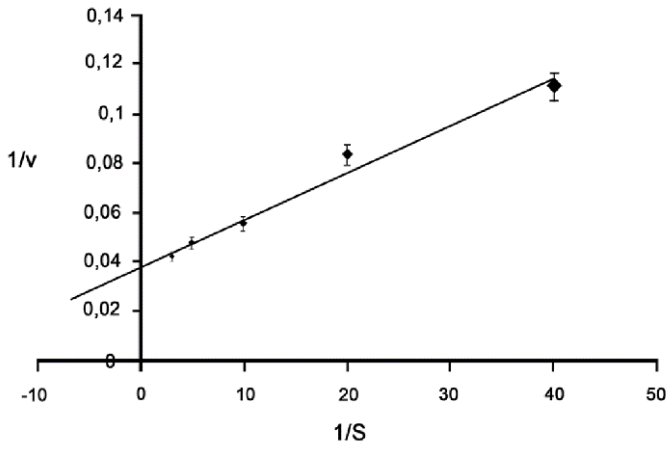

Figure 2. Lineweaver-Burk Plot showing effect of substrate (casein) concentration on protease activity. "V" denotes initial velocity of enzymatic reaction (units are $\mu \mathrm{Mole} / \mathrm{mg} / \mathrm{ml}$ ) while "S" denotes substrate concentration in percentage

\subsubsection{Effect of Inhibitors on Protease Activity}

The complete loss of protease activity happened in the presence of inhibitor 10mM PMSF with relative activity of $7.5 \%$ (Fig. 3C).

Thus, G. candidum protease is categorized as a serine protease. This inhibitor causes covalent and irreversible modifications at the active site residues. $\beta$ mercaptoethanol and cysteine did not affect the protease activity.

4.5.3. Effect of Metal Ions and Organic Solvent on Protease Activity

The G. candidum QAUGC01 protease is not metal dependent. The effect of various metal ion salts such as $\mathrm{Co}^{+2}, \mathrm{Ca}^{+2}, \mathrm{Mn}^{+2}, \mathrm{Cu}^{+2}, \mathrm{Mg}^{+2}, \mathrm{Hg}^{+2}, \mathrm{Cd}^{+2}$ and $\mathrm{Zn}^{+2}$ were checked at $(10 \mathrm{mM})$ concentration on purified protease. Calcium (107\%), magnesium $(96.10 \%)$ and manganese $(93 \%)$ at $10 \mathrm{mM}$ concentration did not affect the protease activity to much significant extent (Fig. 3D).

Protease showed maximum stability in the presence of polar solvents such as methanol, ethanol and butanol with an increasing activity up to $158.7 \%, 164.64 \%$ and 173.10\%, respectively (Fig. 3E).

Table 1. Summary of Purification of Protease from G. candidum QAUGC01

\begin{tabular}{lcccccc}
\hline Purification step & $\begin{array}{c}\text { Volum } \\
\mathbf{e}(\mathbf{m L})\end{array}$ & $\begin{array}{c}\text { Total Protein } \\
(\mathbf{m g})\end{array}$ & $\begin{array}{c}\text { Total activity } \\
(\mathbf{U})\end{array}$ & $\begin{array}{c}\text { Specific activity (U } \\
\left.\mathbf{m g}^{-1}\right)\end{array}$ & $\begin{array}{c}\text { Purification } \\
(\text { fold) }\end{array}$ & $\begin{array}{c}\text { Yield } \\
(\mathbf{\%})\end{array}$ \\
\hline Culture supernatant & 250 & 431.0 & 6510 & 15.10 & 1.0 \\
Ammonium sulfate precipitation & 15 & 38.5 & 4673 & 121.30 & 100 \\
Sephadex G-100 & 3 & 4.35 & 3012 & 692.0 & 71.74 \\
\hline
\end{tabular}

Table 2. Thermodynamics Parameters for Denaturation of Protease

\begin{tabular}{|c|c|c|c|c|c|c|}
\hline Temperature $\left({ }^{\circ} \mathrm{C}\right)$ & Temperature (K) & $K_{d}\left(\min ^{-1}\right)$ & Half-life (min) & $\begin{array}{c}\text { Enthalpy (kJ } \\
\left.\text { mol }^{-1}\right)\end{array}$ & $\begin{array}{c}\text { Free energy }(\mathrm{kJ} \\
\left.\mathrm{mol}^{-1}\right)\end{array}$ & $\begin{array}{c}\text { Entropy }\left(\mathrm{Jmol}^{-1}\right. \\
\left.\mathrm{K}^{-1}\right)\end{array}$ \\
\hline 45 & 318.15 & 0.0049 & 141.43 & 5.21 & 89.87 & -266.10 \\
\hline 50 & 323.15 & 0.0065 & 106.62 & 5.16 & 91.29 & -266.53 \\
\hline S55 & 328.15 & 0.0122 & 56.80 & 5.12 & 92.65 & -266.73 \\
\hline 60 & 333.15 & 0.0179 & 38.72 & 5.08 & 94.11 & -267.24 \\
\hline 65 & 338.15 & 0.0258 & 26.86 & 5.04 & 95.47 & -267.42 \\
\hline 70 & 343.15 & 0.0441 & 15.71 & 5.00 & 96.88 & -267.75 \\
\hline
\end{tabular}


A

B
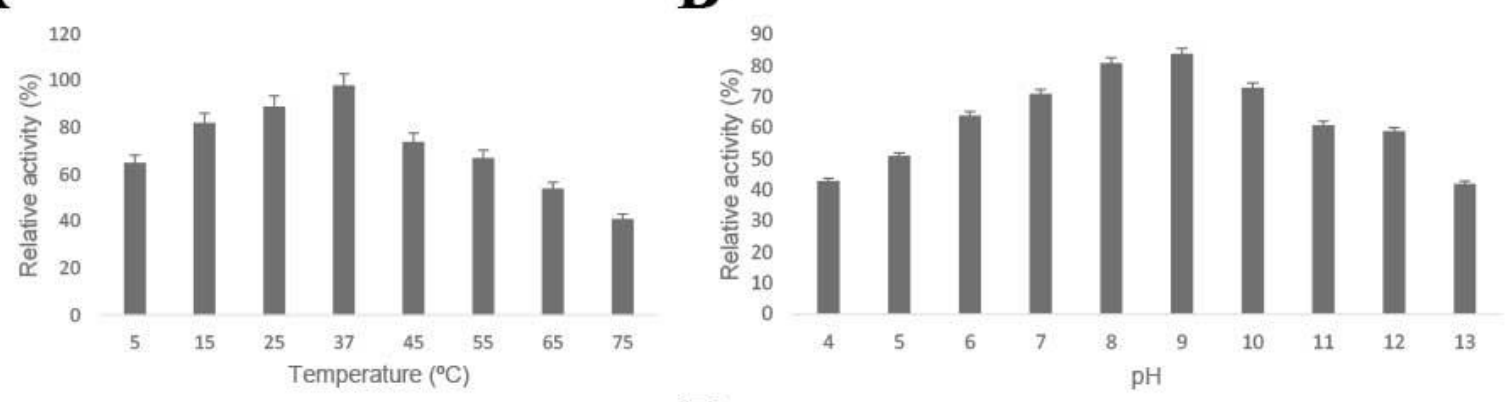

D
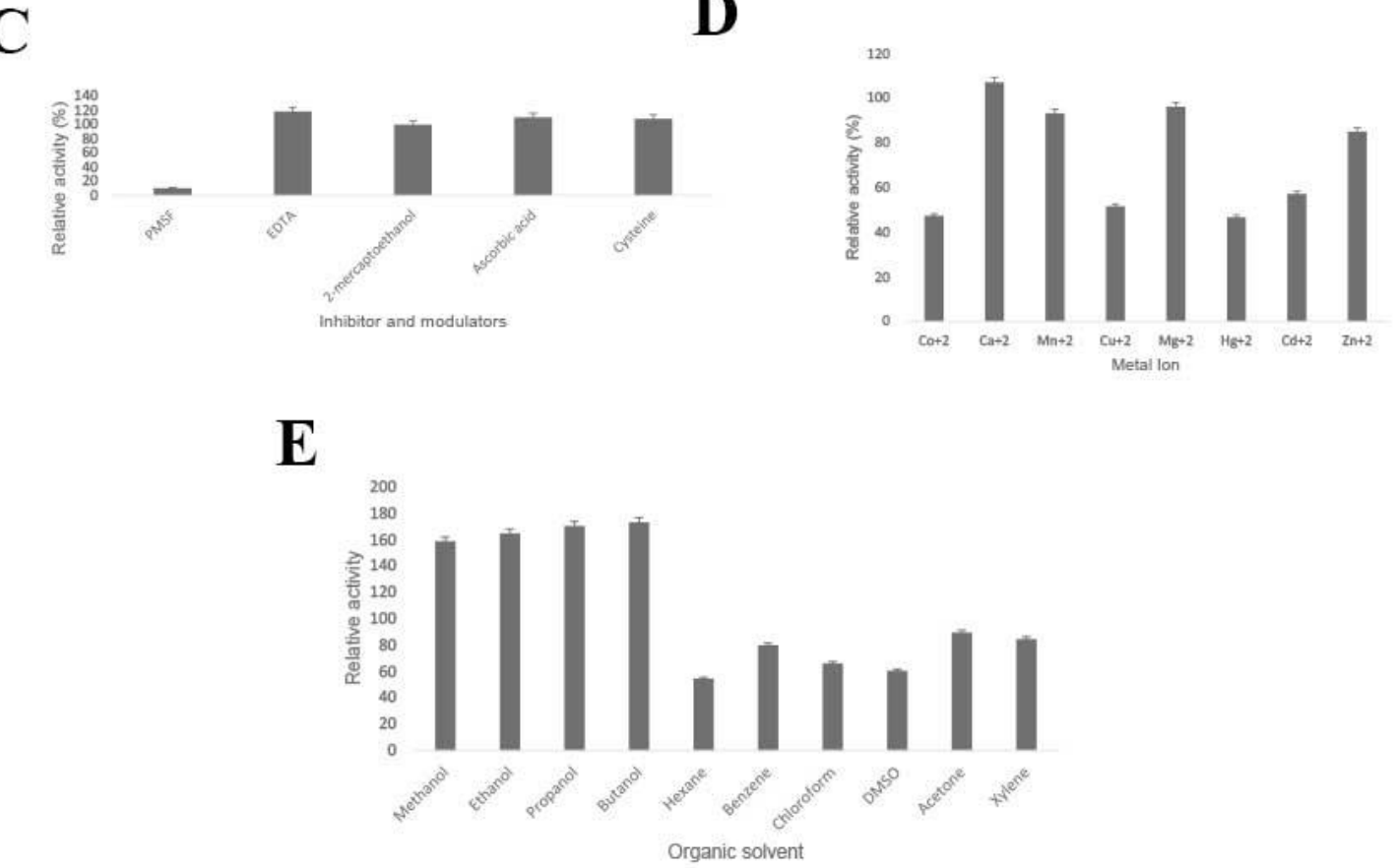

Figure 3. (A) Effect of temperature (B) $\mathrm{pH}(\mathbf{C})$ inhibitors (D) metal ion (E) organic solvent (F) substrate specificity, on the stability and activity of protease without any treatment was taken as $100 \%$. Y error bars indicates the standard deviation among the three replicates which differ significantly at $<0.05$

\subsubsection{Effect of Substrate SPECIFICITY}

Broad range of substrate specificity of the protease was observed in the current study. Among different substrates tested protease showed a better hydrolyzing ability against casein and skim milk (98\% and $95 \%$ of relative activity) followed by gelatin, BSA and casein with $89 \%, 62 \%$ and $35 \%$ relative activity, respectively (Fig. 3F).

\subsection{Thermodynamics of Protease Denaturation}

The resistance of enzymes against temperature is an important criterion for its commercial significance. Purified protease was incubated at 50, 55, 60, 65 and $70^{\circ} \mathrm{C}$. The data obtained from the experiments were plotted as shown in Figure 4.

The values of $K_{d}$ were $0.0122,0.0258,0.0441 \mathrm{~min}^{-1}$ while the half-life calculated were $56.8 \mathrm{~min}, 26.8 \mathrm{~min}$ and $15.7 \mathrm{~min}$ at 55,65 and $70^{\circ} \mathrm{C}$ respectively (Table 2 ). The values of enthalpy, free energy and enthalpy for denaturation of protease are presented in (Table 2).
Moreover less values of entropy shows that the denaturation of protease is a favorable process.

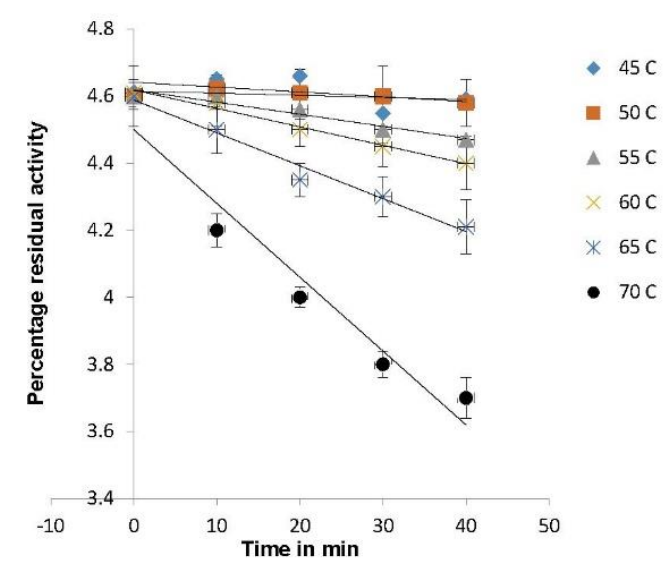

Figure 4. Pseudo-first-order plots for irreversible thermal denaturation of protease at $45-70{ }^{\circ} \mathrm{C}$. The slope of each graph corresponds to the $k_{d}$ (thermal inactivation constant) for the respective temperature 


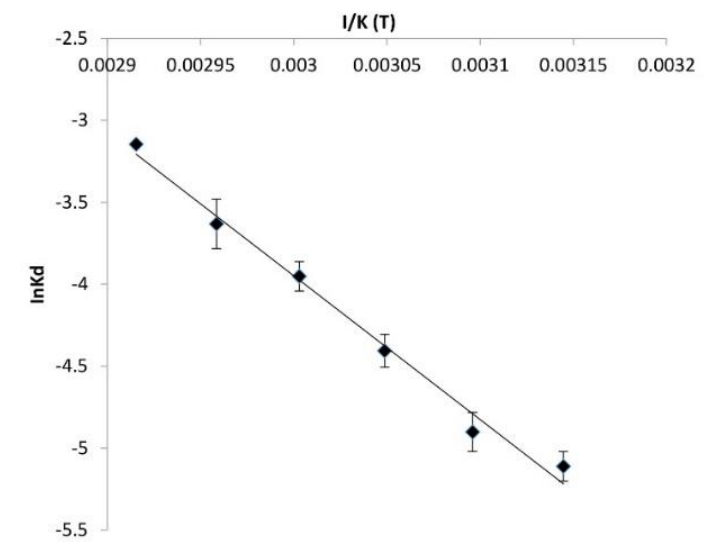

Figure 5. Arrhenius plot to calculate activation energy $E_{\mathrm{a}}$ for irreversible thermal inactivation of protease. $k_{d}$ denotes denaturation constant while $\mathrm{T}$ represents temperature in Kelvin. Ea $=$-slope $\mathrm{x}$ R. while $\mathrm{R}$ is Gas Constant $(8.314 \mathrm{~J} / \mathrm{K} / \mathrm{mol})$.

\section{Discussion}

The present study deals with the evaluation of proteolytic activity of $G$. candidum based on the clear hydrolysis zone formation. The protease activity was found to be strain dependent and this was confirmed by quantifying by standard protease assay. The $G$. candidum QAUGC01 (NCBI accession No. KT280407) showed highest activity and it was used for further studies. Various conditions were considered and maximum specific activity was obtained at $25^{\circ} \mathrm{C}$ at an initial $\mathrm{pH}$ of 4.0 for $72 \mathrm{~h}$ of incubation producing 26.21 U.mL $\mathrm{m}^{-1}$ maximum extracellular protease. Prolonged incubation and static condition showed reduction in the growth and protease production. The longer period of incubation results in the formation of inhibitory substances and/or non-availability of nutrients and this causes a decline in the formation of enzymes. Our results were also corroborated with an alkaline protease from Bacillus sp (24).

Temperature affects the protease synthesis nonspecifically by altering the biochemical reaction rate specifically through inducing or repressing enzyme production. Temperature is an important parameter that controls biochemical pathways (25). In the case of extracellular enzymes, the temperature allows altering of structural properties of plasma membrane. The G. candidum can be cultivated in the temperature range from $5^{\circ} \mathrm{C}$ to $38^{\circ} \mathrm{C}$, with an optimal production around $25{ }^{\circ} \mathrm{C}$ (26). Temperature not only affect protease enzyme production but also growth rate of $G$. candidum. Medium $\mathrm{pH}$ is also important for cellular transport of protein through the membrane bilayer $(27,28)$. G. candidum can grow in broad $\mathrm{pH}$ range ( 3 to 11 ), best at $\mathrm{pH}$ below 4.4 and however, few strains can grow even at $\mathrm{pH}$ 3.4. which makes this organism suitable for industrial use (22).

The present study indicated that protease was stable at wide range of elevated temperature and $\mathrm{pH}$ with maximum range $\left(25-45^{\circ} \mathrm{C}\right)$ and $\mathrm{pH}(8-9)$. The results were in accordance with the earlier report for Bacillus sp (29). It was reported earlier that an alkaline protease from marine yeast Aureobasidium pullulans was stable in the range of $\mathrm{pH} 4.0$ and 12.0 (30). The alkalophilic Bacillus pumilus produced another thermo-stable protease in alkaline $\mathrm{pH} 4.0-12.0$. The results obtained in present study were in agreement with past studies (31, 32).

Proteases have also been categorized according to their sensitivity to various inhibitors. Inhibition studies suggest understanding regarding the nature of an enzyme, its active site nature and cofactor requirements (33). Thus, G. candidum protease is categorized as a serine protease, because the EDTA had no effect on activity, which suggests that the enzyme may not be a metalloprotease and only depends on the mono and divalent cations as stabilizers. However, the EDTAindependent nature of the enzyme suggests that it may be a useful laundry additive (34). It was observed that $\mathrm{Ca}^{+2}$ ions have the ability to stabilize the enzyme structure when exposed to extreme temperature and it depicts its role in stabilizing ternary complex of enzymes (35). However, $\mathrm{Ca}^{+2}$ dependent proteases are less studied and information about them is scarce. Inhibition of proteolytic activity in the presence of cadmium ion $(57.11 \pm 7.5 \%)$ is due to the interaction with disulfide and thiol groups (36).

Protease stability with polar solvents is a very valuable characteristic for fermentation industry (37). The maximum inhibitory effect was observed with non-polar organic solvents such as hexane, benzene, chloroform and DMSO. It has now been realized that the catalytic performance of the enzymes could be correlated with their dynamic properties and interactions with the solvent system. Though, enzymes are generally inactivated or denatured in the presence of non-polar organic solvents. Maximum hydrolytic activity of protease was observed against casein, it is similar to the earlier report from alkaline protease from Bacillus mojavensis $(38,39)$. Extracellular enzyme activity of $G$. candidum is higher in soft cheese than hard cheeses and this also confirms the proteolytic role of G. candidum in semi-solid indigenous fermented milk product Dahi (7). Half-life and $K_{d}$, clearly depicted the mesophilic nature of enzyme as compared to thermophilic nature (23). The difference between thermostability and thermophilicity is the resistance to the unfolding is assessed at various temperature. While in case of thermophilicity, the ability of enzyme to carry out the reaction at higher temperatures are assessed. The activation energy for denaturation of protease (Fig. 5) was found to be less than that was obtained from xylanases reported by Bokhari et al., (23). The enzyme inactivation at higher temperatures is denoted by the breakdown of non-covalent interactions resulting in increase in enthalpy. The denaturation of enzyme and resulting expansion in the enzyme structure results in increase in entropy $(40,41)$. The higher free energy and 
lower enthalpy values depicted that the enzyme is only meagerly thermostable at the given temperatures.

In the present work, G. candidum QAUGC01 strain isolated from indigenously fermented milk product was found suitable for production of an extracellular protease. This protease has interesting biochemical, thermodynamic and kinetic properties. The main characteristics features of this protease are: Serine type, alkaliphilic, and thermostability are the main characteristics of this protease from G. candidum QAUGC01.

\section{Acknowledgement}

We are thankful to Quaid-i-Azam University, Islamabad Pakistan for providing us research grant to accomplish the present study.

\section{References}

1. Mothe T, Sultanpuram VR. Production, purification and characterization of a thermotolerant alkaline serine protease from a novel species Bacillus caseinilyticus. 3 Biotech. 2016;6(1):53. doi: 10.1007/s13205-016-0377y pmid: 28330122

2. Ramamoorthy SK, Gnanakkan Aa, Kathirvel I. Response surface method to optimize the low cost medium for protease production using anchovy meal from ascidian associated Bacillus sp. GA CAS10. Afr J Biotechnol 2014;13(27):2741-2749. doi: 10.5897/ajb2014.13891

3. Juturu V, Wu JC. Microbial cellulases: Engineering, production and applications. Renew Sustain Energy Rev. 2014;33:188-203. doi: 10.1016/j.rser.2014.01.077

4. Rosenberg L, Lapid O, Bogdanov-Berezovsky A, Glesinger R, Krieger Y, Silberstein E, et al. Safety and efficacy of a proteolytic enzyme for enzymatic burn debridement: a preliminary report. Burns. 2004;30(8):843-850. doi: 10.1016/j.burns.2004.04.0 10 pmid: 15555800

5. de Castro RJS, Sato HH. Production and biochemical characterization of protease from Aspergillus oryzae: An evaluation of the physical-chemical parameters using agroindustrial wastes as supports. Biocatal Agricult Biotechnol. 2014;3(3):20-25. doi: 10.1016/j.bcab.2013 .12 .002

6. Agrawal D, Patidar P, Banerjee T, Patil S. Production of alkaline protease by Penicillium sp. under SSF conditions and its application to soy protein hydrolysis. Proc Biochem. 2004;39(8):977-981. doi: 10.1016/s0032-9592(03)00212-7

7. Imran M, Desmasures N, Vernoux J-P. Complex Microbial Communities as Part of Fermented Food Ecosystems and Beneficial Properties: CRC Press; 2012.

8. Mounier J, Goerges S, Gelsomino R, Vancanneyt M, Vandemeulebroecke K, Hoste B, et al. Sources of the adventitious microflora of a smear-ripened cheese. $J$ Appl Microbiol. 2006;101(3):668-681. doi: 10.1111/j.1365-2672.2006.02922.x pmid: 16907817

9. Barkaat M. [Study of the impact of microbial diversity on nutritional and organoleptic quality of indigenous fermented milk product (Dahi)]. Islamabad, Pakistan: Quaid-i-Azam University; 2015.
10. Chamba JF, Jamet E. Contribution to the safety assessment of technological microflora found in fermented dairy products. Int $J$ Food Microbiol. 2008;126(3):263-266. doi: 10.1016/j.ijfoodmicro.200 7.08.001 pmid: 17900730

11. Pottier I, Gente S, Vernoux JP, Gueguen M. Safety assessment of dairy microorganisms: Geotrichum candidum. Int J Food Microbiol. 2008;126(3):327-332. doi: $\quad 10.1016 / j . j$.jfoodmicro.2007.08.021 pmid: 17869364

12. Bourdichon F, Casaregola S, Farrokh C, Frisvad JC, Gerds ML, Hammes WP, et al. Food fermentations: microorganisms with technological beneficial use. Int $J$ Food Microbiol. 2012;154(3):87-97. doi: 10.1016/j.ijfoodmicro.2011.12.030 pmid: 22257932

13. Morel G, Sterck L, Swennen D, Marcet-Houben M, Onesime D, Levasseur A, et al. Differential gene retention as an evolutionary mechanism to generate biodiversity and adaptation in yeasts. Sci Rep. 2015;5:11571. doi: 10.1038/srep11571 pmid: 26108467

14. Vazquez S, Ruberto L, Mac Cormack W. Properties of extracellular proteases from three psychrotolerant Stenotrophomonas maltophilia isolated from Antarctic soil. Polar Biol. 2004;28(4):319-325. doi: 10.1007/s00300-004-0673-6

15. Gueguen M, Lenoir J. Aptitude de l'espèce Geotrichum candidum à la production d'enzymes protéolytiques. Le Lait. 1975;55(543-544):145-162. doi: 10.1051/lait:19 75543-5449

16. Kunitz N. Methods of enzymatic analysis. London: Verlag Chemic Academic press; 1965.

17. Tsuchiya K, Nakamura Y, Sakashita H, Kimura T. Purification and characterization of a thermostable alkaline protease from alkalophilic Thermoactinomyces sp. HS682. Biosci Biotechnol Biochem. 1992;56(2):246250. doi: 10.1271/bbb.56.246 pmid: 1368301

18. Shaheen M, Shah AA, Hameed A, Hasan F. Influence of culture conditions on production and activity of protease from Bacillus subtilis BS1. Pak J Bot. 2008;40(5):2161-2169.

19. Quiroga E, Priolo N, Marchese J, Barberis S. Stability of araujiain, a novel plant protease, in different organic systems. Acta Farmac Bonaerense. 2005;24(2):204.

20. Qadar SAU, Shireen E, Iqbal S, Anwar A. Optimization of protease production from newly isolated strain of Bacillus sp. PCSIR EA-3. Indian J Biotechnol. 2009;8:286-290.

21. Kiranmayee R, M LN. Alkaline Protease from Bacillus firmus 7728. Afr J Biotechnol. 2007;6(21):2493-2496. doi: 10.5897/ajb2007.000-2395

22. Boutrou R, Gueguen M. Interests in Geotrichum candidum for cheese technology. Int J Food Microbiol. 2005;102(1):1-20. doi: 10.1016/j.ijfoodmicro.2004.1 2.028 pmid: 15924999

23. Bokhari SAI, Latif F, Rajoka MI. Purification and characterization of xylanases from Thermomyces lanuginosus and its mutant derivative possessing novel kinetic and thermodynamic properties. World $J$ Microbiol Biotechnol. 2008;25(3):493-502. doi: 10.1007/s11274-008-9915-Z

24. Uyar F, Baysal Z. Production and optimization of process parameters for alkaline protease production by a newly isolated Bacillus sp. under solid state 
fermentation. Proc Biochem. 2004;39(12):1893-1898. doi: 10.1016/j.procbio.2003.09.016

25. Souza PM, Werneck G, Aliakbarian B, Siqueira F, Ferreira Filho EX, Perego P, et al. Production, purification and characterization of an aspartic protease from Aspergillus foetidus. Food Chem Toxicol. 2017;109(Pt 2):1103-1110. doi: 10.1016/j.fct.2017.0 3.055 pmid: 28359876

26. Wyder MT. Identification and characterization of the yeast flora in Kefyr and smear ripened cheese. Switzerland: Swiss Federal Institute of Technology; 1998.

27. Ellaiah P, Srinivasulu B, Adinarayana K. A review on microbial alkaline proteases. J Sci Ind Res. 2002;61:690704.

28. Venugopal M, Saramma AV. Characterization of alkaline protease from Vibrio fluvialis strain VM10 isolated from a mangrove sediment sample and its application as a laundry detergent additive. Proc Biochem. 2006;41(6):1239-1243. doi: 10.1016/j.procb io.2005.12.025

29. Deng A, Wu J, Zhang Y, Zhang G, Wen T. Purification and characterization of a surfactant-stable high-alkaline protease from Bacillus sp. B001. Bioresour Technol. 2010;101(18):7111-7117. doi: 10.1016/j.biortech.201 0.03.130 pmid: 20417096

30. Gupta R, Beg QK, Lorenz P. Bacterial alkaline proteases: molecular approaches and industrial applications. Appl Microbiol Biotechnol. 2002;59(1):1532. doi: $10.1007 /$ s00253-002-0975-y pmid: 12073127

31. Ma C, Ni X, Chi Z, Ma L, Gao L. Purification and characterization of an alkaline protease from the marine yeast Aureobasidium pullulans for bioactive peptide production from different sources. Mar Biotechnol (NY). 2007;9(3):343-351. doi: 10.1007/s10126-0066105-6 pmid: 17345116

32. Habbeche A, Saoudi B, Jaouadi B, Haberra S, Kerouaz $\mathrm{B}$, Boudelaa $\mathrm{M}$, et al. Purification and biochemical characterization of a detergent-stable keratinase from a newly thermophilic actinomycete Actinomadura keratinilytica strain Cpt29 isolated from poultry compost. J Biosci Bioeng. 2014;117(4):413-421. doi: 10.1016/j.jbiosc.2013.09.006 pmid: 24140106
33. North M. Comparative biochemistry of the proteinases of eukaryotic microorganisms. Microbiol Rev. 1982;46:308-315.

34. Raval VH, Pillai S, Rawal CM, Singh SP. Biochemical and structural characterization of a detergent-stable serine alkaline protease from seawater haloalkaliphilic bacteria. Proc Biochem. 2014;49(6):955-962. doi: 10.1016/j.procbio.2014.03.014

35. Okamoto M, Yonejima Y, Tsujimoto Y, Suzuki Y, Watanabe Z. A thermostable collagenolytic protease with a very large molecular mass produced by thermophilic Bacillus sp. strain MO-1. Appl Microbiol Biotechnol. 2001;57(1-2):103-108. doi: 10.1007/s002 530100731

36. Annamalai N, Rajeswari MV, Sahu SK, Balasubramanian T. Purification and characterization of solvent stable, alkaline protease from Bacillus firmus CAS 7 by microbial conversion of marine wastes and molecular mechanism underlying solvent stability. Proc Biochem. 2014;49(6):1012-1019. doi: 10.1016/j.procb io.2014.03.007

37. Najafi MF, Deobagkar D, Deobagkar D. Potential application of protease isolated from Pseudomonas aeruginosa PD100. Electron $J$ Biotechnol. 2005;8(2):197-203. doi: 10.2225/vol8-issue2-fulltext5

38. Beg QK, Gupta R. Purification and characterization of an oxidation-stable, thiol-dependent serine alkaline protease from Bacillus mojavensis. Enzyme Microb Technol. 2003;32(2):294-304. doi: 10.1016/s01410229(02)00293-4

39. Mohammadian M, Farzampanah L, Behtash-oskouie A, Majdi S, Mohseni G, Imandar M, et al. A biosensor for detect nitrite (NO2-) and hydroxylamine (nh2oh) by using of hydroxylamine oxidase and modified electrode with $\mathrm{ZnO}$ nanoparticles. Int $J$ Electrochem Sci. 2013;8(9):11215-11227.

40. Ward OP, Moo-Young M. Thermostable enzymes. Biotechnol Adv. 1988;6(1):39-69. doi: 10.1016/07349750(88)90573-3 pmid: 14543441

41. Muhammad A, Ali S, Bokhari I. Purification and characterization of extracellular lipase by Geotrichum candidum of dairy origin. Pak J Bot. 2017;49(2):757761. 